\title{
NOTAS SOBRE ALGUNS DOS LIMITES DO ENSINO DA FILOSOFIA E SUAS CONDIÇÕES DE POSSIBILIDADE
}

\author{
Rodrigo Pelloso Gelamo ${ }^{1}$ \\ Pedro Bravo de Souza ${ }^{2}$ \\ Aline Oliveira $^{3}$
}

\section{Palavras iniciais}

"Seria bom, Agatão, se de tal natureza fosse a sabedoria que do mais cheio escorresse ao mais vazio, quando um ao outro nos tocássemos, como a água dos copos que pelo fio de lá escorre do mais cheio ao mais vazio" Sócrates (O Banquete)

Este texto, resultado de um projeto que envolve tanto o âmbito da pesquisa quanto o da extensão universitária, foi motivado por um intenso ano de atividades filosóficas com crianças. Neste contexto, diferentes problemáticas emergiram, tais como a (im)possibilidade de se saber que alguém filosofa - relacionada, por exemplo, à escrita e às questões filosóficas - assim como a procura por um ambiente mais propício à filosofia. Ao pensar tais problemáticas, cremos ter encontrado alguns dos limites e das condições inerentes ao ensino da filosofia com crianças, os quais apresentaremos na confluência de alguns autores que discutem essas questões, ou nos dão condições de fazê-lo, tais como Cerletti, Foucault, Benjamin e Lipman.

De início, é preciso que indiquemos nosso ponto de partida: o projeto de extensão intitulado "O Ensino da Filosofia em espaços não-formais". Tal projeto é resultado da parceria entre a (instituição a que pertencemos) e a (mantenedora do projeto), sendo esta responsável pela organização não governamental (ONG)

\footnotetext{
${ }^{1}$ Universidade Estadual Paulista Júlio de Mesquita Filho. E-mail: gelamo@gmail.com.

${ }^{2}$ Universidade Estadual Paulista Júlio de Mesquita Filho. E-mail:pedrobravodesouza@hotmail.com.

${ }^{3}$ Universidade Estadual Paulista Júlio de Mesquita Filho. E-mail: al.si.oliveira@gmail.com.

GELAMO, Rodrigo Pelloso; SOUZA, Pedro Bravo; OLIVEIRA, Aline. Notas sobre alguns dos limites do Ensino da Filosofia com crianças e suas condições de possibilidade. Revista Sul-Americana de Filosofia e Educação. Número 23: nov/2014-abr/2015, p. 487-505.
} 
nomeada Projeto (nome do projeto), onde se realizam as atividades de filosofia com crianças.

As veredas desse projeto foram uma flecha atirada desde outro projeto realizado no mesmo contexto, mas com outras finalidades, em um momento no qual nossa preocupação central era o papel da experiência no ensino da filosofia. $\mathrm{O}$ projeto a que nos referimos intitulava-se "Transmissão de conhecimento ou experiência no ensino da filosofia: limites e possibilidades". Com ele tentávamos descobrir a possibilidade de um ensino da filosofia que não fosse baseado somente na transmissão abstrata de conhecimentos, mas que permitisse uma experiência de pensar passível de ser compreendida como uma experiência filosófica.

Nesse sentido, nossa proposta de atividades se amparava em um exercício de práticas de Filosofia com crianças, pois acreditamos que a transmissibilidade filosófica precisa acontecer sempre na relação entre dois (ou vários) indivíduos. De certa forma, entendemos essa relação, que chamamos de ensino, como um encontro com um conhecimento ao qual ambos, aquele que ensina e aquele que aprende, podem ter acesso. Por isso, pensamos que o ensino da filosofia aconteça no encontro com os educandos e não como um saber que já está pré-determinado e que precisa ser transmitido para alguém, como algo exterior, talvez vazio e ausente. Nesse sentido, estamos de acordo com a concepção de ensino de Freire (2011) na Pedagogia do Oprimido. Para ele, a educação tem de ser entendida como "aquela que tem de ser forjada com (...) e não para (...), enquanto homens ou povos, na luta incessante de recuperação de sua humanidade" (FREIRE, 2011, p. 4).

Igualmente, pode-se notar que consideramos a relação pesquisa-extensão de extrema importância e que, especialmente para essa reflexão, é um elemento não passivel de separação, porque pensamos que a extensão fornece elementos que problematizam a pesquisa, e esta, afetada pela extensão, possibilita entender e indicar caminhos para melhor realizá-la. Desse modo, concordamos com Kohan e Olarieta (2012, p. 19) quando fazem a seguinte afirmação sobre a relação Pesquisa-Extensão, ao se referirem ao alcance do Projeto de extensão 
desenvolvido por eles, Em Caxias a Filosofia en-caixa?? "Para parafrasear Kant, a extensão sem pesquisa é vazia e a pesquisa sem extensão é cega".

Na realidade, foi com grata surpresa que descobrimos, a partir da leitura de A escola pública aposta no pensamento (KOHAN; OLARIETA, 2012), muitos pontos em comum entre o nosso projeto e o coordenado por Kohan. Já sabíamos de sua existência, mas não da proximidade entre deles. Por isso, sentimos a necessidade de apresentar algumas aproximações $e$ diferenças entre os dois projetos que pensamos ser complementares.

Grosso modo, o projeto Em Caxias a Filosofia en-caixa? busca propiciar a filosofia não como saber ou conteúdo, mas como experiência de pensamento entre estudantes e professores. Para tanto, disponibiliza aos professores cursos intensivos de formação amparadas em uma série de momentos para compor uma experiência filosófica. Tais momentos são: a) uma disposição inicial, baseada em uma atividade para facilitar e enriquecer a relação das crianças com os textos $e$ a discussão filosófica; b) a vivência (leitura) de um texto, usado para forçar o pensamento; c) a problematização do texto e o levantamento de temas e questões; d) a escolha de temas e questões para serem discutidos; e) o diálogo; e f) o destaque ou recuperação de alguma dimensão da experiência e recriação de conceitos, apresentando-os de maneira diferente.

Dessa maneira é possível criar um ambiente agradável e estimulante que inspire a confiança das crianças e a vontade de fazer parte dessa experiência. Além disso, o projeto procura integrar as dimensões afetiva $e$ intelectual dos participantes, bem como proporcionar uma postura filosófica que se dirige mais ao questionamento do que à certeza.

Por outro lado, pudemos notar igualmente algumas diferenças entre ambos os projetos. Talvez a principal delas seja o lugar de desenvolvimento das atividades: o espaço não formal de ensino, no nosso caso, e a escola, no caso do projeto de Kohan. No nosso projeto, utilizamos os diferentes espaços da ONG, aproveitando o que cada ambiente nos oferece, em especial o espaço aberto, o entre as salas. No projeto de Kohan, em cada escola existe uma "Sala do Pensamento", que é um ambiente construído especificamente para a realização das 
experiências filosóficas com as crianças. Ela é estruturalmente adaptada para instigar as crianças, com grandes portas e janelas, um espaço retangular para as crianças se sentarem ao chão, além de uma claraboia.

Outra característica que diferencia nossos projetos é o uso de textos que, no nosso caso, não é muito frequente. Como as nossas atividades são realizadas com algumas crianças que ainda não sabem ler ou não possuem um completo domínio da leitura, o uso contínuo de textos se torna inviável. Ocupamo-nos, então, de uma dinâmica dialógica obtida através de temas retirados de atividades práticas. Nesse ponto, contudo, nosso projeto tem muito em comum com o de Duque Caxias. Em ambos a postura de quem realiza as atividades (o professor, no caso deles, e nós mesmos, no nosso) deve ser pautada em interferir o mínimo possível na discussão das crianças. Além de procurarmos incentivar a (des)continuidade da discussão e propiciarmos espaço para que todos participem dela, a interferência só é feita diante do pedido de maiores explicações daquilo que é dito pelas crianças.

A partir dessa dimensão dialógica presente tanto em nosso projeto quanto no de Caxias, pode-se estabelecer uma relação na qual várias questões surgem $e$ várias pessoas são afetadas: os professores, as crianças, ou ambos. Como nossa proposta deslocava, em suma, nosso lugar de professores - posição depositária do saber acumulado por certa tradição e que se destina para o aluno -, nas atividades com as crianças, fomos forçados a pensar diversos questionamentos e mudanças de olhar. Isso produziu em nós a necessidade de fazer um exercício de pensamento e de escrita no qual pudemos nos (re)posicionar, (re)pensando nossas práticas filosóficas e, assim, sentir, com o processo de escrita deste artigo, a força do caminho que ora nos coloca frente a essa tarefa.

\section{A flecha problemática do projeto: quando o alvo é permanecer rasgando o ar}

Ao longo desse projeto, vários problemas afetaram todos nós, seus participantes, sugerindo a necessidade de maiores aprofundamentos para tratá-los. Em um momento anterior, amparados em Fernando Bárcena, Michel Foucault e 
Jaccques Rancière, pensamos principalmente o papel da experiência no ensino da Filosofia ${ }^{4}$.

Dizíamos anteriormente que esse projeto tinha sido pensado a partir de uma flecha lançada por outra experiência desenvolvida nos anos anteriores. Essa flecha chegou até nós com uma série de problemáticas que não havíamos tido condições de responder a contento na investigação anterior e que se mantinham tensas, ainda provocando nosso pensamento.

Naquele momento Rancière (2002) nos mostrou que é insuficiente e deveras problemático um ensino baseado somente na transmissão abstrata de conteúdos. Com efeito, nessa estratégia de ensino há uma hierarquização de saber pressuposta: o professor que conhece e precisa transmitir seu conhecimento ao aluno, o qual, visto dessa maneira, é vazio, apto somente a receber informações ${ }^{5}$.

Destarte, gera-se também uma lógica explicadora, isto é, o professor dará explicações sobre um texto de filosofia, por exemplo, baseado em explicações de outros comentadores que quiçá basearam-se também em outros. O contato que o aluno tem com o objeto ensinado se dá prioritariamente através da explicação de seu mestre, que é capturado por essa lógica que exige dele um regresso infinito à explicação, não oferecendo maiores condições de acesso ao objeto, a não ser por essa mediação abstrata.

A partir dessas provocações que Rancière nos ofereceu, pudemos repensar nossa prática com as crianças vendo o quanto estabelecíamos uma relação de saber/poder com elas, que por nós não era questionada. Para exemplificar, em uma de nossas atividades, pedimos que os educandos desenhassem a si mesmos $e$ aos outros em papel pardo e colassem recortes de revistas que lhes possibilitassem uma identificação. A atividade gerou importantes questionamentos. Contudo, quando um educando foi questionado a respeito do motivo pelo qual ele havia feito seu desenho, sua resposta foi a de que os educadores o haviam mandado. Foi nesse contexto, portanto, que a leitura de Rancière surgiu e nos fez pensar em diferentes maneiras de nos relacionarmos com as crianças e com o conhecimento.

\footnotetext{
${ }^{4}$ A referência ao texto foi omitida para não quebrar o sigilo de autoria.

${ }^{5}$ Freire (2011), em outro contexto, também faz uma crítica a esse modelo de educação com o conceito de concepção bancária da educação.
} 
Em suma, foram essas as problemáticas que nos fizeram pensar e que nos permitem caminhar em outros problemas no presente momento. De todo modo, no período apresentado acima, pudemos concluir que não sabíamos se havíamos ensinado ou não o filosofar às crianças, mas certamente aprendemos a fazer o exercício do filosofar face aos problemas que nos iam obrigando a pensar ${ }^{6}$. Percebemos, por conseguinte, que para fazer filosofia era necessário mais do que somente entrar em contato com a História da Filosofia, mas nos defrontarmos com todas as nossas fragilidades diante dos problemas que a vida nos apresentava: especificamente nesse caso, a (im)possibilidade de filosofar e/ou fazer filosofia com aquelas crianças.

Ademais, foi com esses pensamentos que iniciamos as atividades que moveram nosso pensamento para a escrita desse artigo. Neste momento, os problemas que nos afetam podem ser enunciados da seguinte maneira: (i) Como, se é que possível, perceber que alguém pratica o filosofar? $\mathrm{E}$ (ii) de que modo poder-se-ia criar um ambiente no e pelo qual a filosofia tenha mais possibilidade de ser exercida?

Tais problemas puderam ser enunciados quando deslocamos nosso pensamento para a hipótese de que, muito possivelmente, no ensino da Filosofia trabalha-se com várias limitações. A primeira que a nós se apresentou foi uma certa necessidade ${ }^{7}$ de haver no ensino da Filosofia uma Filosofia pressuposta.

Entendemos que essa própria filosofia pressuposta pode condicionar as ações do professor para com os alunos, tornando-se assim um dispositivo nos termos apresentado por Agamben $(2009)^{8}$. No entanto, parece que não há como escapar desse condicionamento, ou melhor, dessa dispositividade. Aliás, caso não seja pressuposto uma Filosofia quiça se ensine tudo menos ela própria. Portanto,

\footnotetext{
${ }^{6}$ A referência ao texto foi omitida para preservar a autoria desse texto.

${ }^{7}$ Apropriando-nos de Aristóteles, compreendemos necessidade como "o que não pode ser diferente do que é" (Met, $\Delta, 1014$ a 34). Vê-se assim a problematicidade de tal limite no ensino da Filosofia.

8 "Chamarei literalmente de dispositivo qualquer coisa que tenha de algum modo a capacidade de capturar, orientar, determinar, interceptar, modelar, controlar e assegurar os gestos, as condutas, as opiniões e os discursos dos seres viventes. Não somente, portanto, as prisões, os manicômios [...] mas também a caneta, a escritura, a literatura, a filosofia, a agricultura..." (AGAMBEN, 2009, p. 41).
} 
Esto exhibe que no se puede enseñar filosofía "desde ningún lado", en una aparente asepsia o neutralidad filosófica. Siempre se asume y se parte, explícita o implícitamente, de ciertos contextos o condiciones, que conviene vislumbrar, porque es esto lo que seguramente se aprenderá (CERLETTI, 2012, p.128).

Se sempre se parte de certos contextos ou condições para ensinar a Filosofia, qual é o nosso? Sentimo-nos ainda em um momento inoportuno para tratar tal problema, pois vimos que muitas vezes um professor de filosofia carrega um embrulho que vê, porém não é visto e, assim, tal professor pode repetir com o poeta de Itabira o seguinte verso: "Não estou vazio/ não estou sozinho/ pois anda comigo/ algo indescritível" (ANDRADE, 2009, p. 32).

Todavia, se considerarmos a hipótese acima de Cerletti, e pensarmos conjuntamente com Maugüé, para quem o ensino da filosofia vale o pensamento daquele que a ensina ${ }^{9}$, podemos nos perguntar: o que as crianças com as quais procuramos filosofar aprenderam com aquilo que estávamos fazendo ali? Mas, assim que enunciamos tal problema, um aparentemente anterior nos afetou: como se sabe que alguém filosofa? Ou melhor, como é possível saber que alguém está filosofando?

Tendo como pano de fundo esses problemas aqui apresentados, nosso projeto se desenvolveu. Vamos, a seguir, tentar apresentar o resultado daquilo que foi possível pensarmos a partir dos problemas e das vivências que tivemos com as crianças do (nome do projeto).

\section{Dos limites da escrita e do perguntar filosófico}

Costumeiramente pode-se ter a hipótese de que se alguém, homem ou mulher, filosofou, então tal pessoa deixou uma obra escrita na qual esse exercício do filosofar foi, de certa maneira, expresso. Desse modo, talvez pudéssemos pensar que um texto escrito por um filósofo é o indício de que ele tenha filosofado.

9 Referimo-nos à seguinte passagem: "O que dificulta o ensino da moral, da lógica ou da estética é, como procuraremos demonstrar, que nestas delicadas disciplinas o ensino vale o que vale o pensamento daquele que as ensina. A Filosofia é o Filósofo" (MAUGÜÉ, 1955, p. 643). 
Todavia, será que a escrita de textos cujos autores são filósofos é consequente do filosofar? É tal escrita a expressão maior, ou única, do exercício de quem pratica a filosofia?

Longe de querermos entrar na profunda relação entre escrita e oralidade, e em todos os problemas que daí poderiam derivar, vamos aqui, esboçar, apoiandonos em algumas das contribuições de Foucault, uma certa crítica a essa confiabilidade muitas vezes extrema do filosofar contido na escrita e tão somente nela.

Michel Foucault, em um de seus últimos cursos no Collège de France intitulado O Governo de si e dos outros (no original: Le Gouvernement de Soi et des Autres), especificamente na aula de 16 de Fevereiro de 1983, trata de um assunto bastante pertinente a nossa problematização: a recusa da escrita por um dos primeiros filósofos: Platão. No contexto de tal aula, o filósofo francês comenta a Carta VII de Platão, onde se vê o fracasso de Dionísio face a um procedimento a que Platão tê-lo-ia submetido. Tal procedimento encontra-se na seguinte passagem, da qual destacamos os seguintes trechos:

Existe un procedimiento para realizar esta comprobación que no carece de nobleza y es verdaderamente adecuado para emplearlo con los tiranos, sobre todo si están repletos de ideas mal entendidas, cosa que yo advertí en cuanto llegué que padecía Dionisio en alto grado. A esta clase de personas hay que mostrarles la empresa filosófica en toda su amplitud, su verdadero carácter, las dificultades que ofrece y el esfuerzo que significa. [...] Inmediatamente pone a contribución todos sus esfuerzos y los de la persona que dirige sus pasos, y no cesa hasta dar fin a la empresa o adquirir fuerzas suficientes para poder caminar solo sin necesidad de guía. [...] Esta es una prueba manifiesta $e$ infalible para emplearla con las personas cómodas $e$ incapaces de esforzarse, de modo que no pueden inculpar a quien las dirige, sino ellos a sí mismos, al no ser capaces de seguir las prácticas adecuadas al fin perseguido. (PLATON, 1954, p.85: 340b - 341b) [grifo nosso].

Podemos notar que esse fracasso se deu pois, segundo Platão, Dionísio não teria conseguido atingir as práticas adequadas ao fim que perseguia, isto é, as práticas da filosofia. Por que o insucesso de Dionísio? 
Para Foucault, por dois motivos: (i) o primeiro refere-se à recusa de Dionísio em escolher o longo caminho da filosofia, presumindo ele, já na primeira lição, saber das coisas mais importantes, embora sem as entender; (ii) o segundo motivo, que a nós interessa grandemente, refere-se ao fato de que Dionísio escreveu um tratado de Filosofia. Diz Foucault:

E é no fato de ter escrito esse tratado de filosofia que Platão enxerga o sinal de que ele não era capaz de encontrar o real da filosofia. O texto escrito por Dionísio foi, de fato, escrito depois da visita de Platão, e Platão evoca-o simplesmente como uma espécie de sinal a posteriori de que na verdade sua visita não podia ser bem-sucedida, porque Dionísio era capaz de ser aquele que, um pouco mais tarde, para atestar seu valor filosófico pessoal e mostrar que na realidade os erros eram de Platão, devia escrever um tratado sobre as questões mais importantes da filosofia. E com isso, diz Platão, ele cometeu dois erros. (FOUCAULT, 2010, p.224).

Mas quais, então, foram os erros cometidos por Dionísio? E qual é a possivel relação desses erros com nossa problemática no ensino da Filosofia com crianças?

Um deles é que ele quis se passar por autor de textos que, na verdade, eram apenas a transcrição das lições que recebera. O outro, mais importante a nós, é que não se pode falar dessa maneira das coisas essenciais da filosofia, pois o discurso filosófico não assume a forma das mathémata, entendida em seu duplo sentido de conhecimentos e fórmulas do conhecimento. Não é dessa maneira, segundo Platão, que a filosofia é transmitida. Ela não pode, portanto, ser reduzida a fórmulas do conhecimento como acontece em outras áreas do saber ${ }^{10}$. Qual é, por conseguinte, a realidade de sua prática? E como ela é então transmitida? Platão afirma que:

Desde luego una obra mía referente a estas cuestiones no existió ni existirá jamás; no se puede, en efecto, reducirlas a

10 A justificativa de Platão é de ordem epistemológica e de extrema dificuldade para aqui transcrevermos. Mesmo assim, podemos dar indícios dessa justificativa. Platão defende que há cinco níveis de conhecimento, sendo três relativos ao conhecimento das coisas: nome, definição e imagem; o quarto é o domínio que tem como objeto as qualidades das coisas; por fim, tem-se o quinto, que é o conhecimento do que as coisas são (tó on). A filosofia estaria no quinto nível e, portanto, ocorre por um trabalho de fricção contínua de um conhecimento no outro que a escrita não poderia transmitir. 
expresión [ $\mu \alpha \theta \eta \dot{\mu} \mu \alpha \tau \alpha$, máthemata], como sucede com outras ramas del saber, sino que como resultado de una prolongada intimidad con el problema mismo y de la convivencia

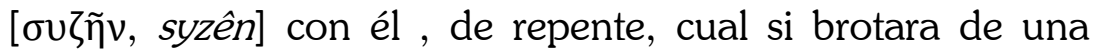
centella, se hace la luz en el alma y ya se alimenta por sí misma. (PLATON, 1954, p. 87: 341c-d).

Comentando essa passagem, afirma Foucault:

Pois bem, ele diz: a filosofia se adquire por "synousía peri to prâgma"'. E um pouco adiante ele utiliza o verbo syzên. Synousía é o ser com, é a reunião, é a conjunção. A palavra synousía tem inclusive, com frequência, no vocabulário grego ordinário, o sentido de conjunção sexual. Aqui não há de modo algum essa conotação, e não creio que se deva forçar a interpretação dizendo que há como que uma relação de conjunção sexual de quem filosofa com a filosofia. Mas quem deve se submeter à prova da filosofia deve "viver com", deve, empreguemos a palavra, "coabitar" com ela aqui também, vocês sabem, com os possíveis sentidos da palavra coabitar. Que aquele que filosofa tenha de coabitar com ela, é o que vai constituir a própria prática da filosofia e sua realidade, synousía: coabitação. Syzên: viver com. (FOUCAULT, 2010, p. 225).

Frente a isso, a filosofia poderia ser transmitida através de éndeixis, isto é, através de estruturas de indicações (FOUCAULT, 2010, p. 227). Em suma, podemos aqui concluir que a escrita ${ }^{11}$ não é suficiente, e talvez nem mesmo necessária, para expressar o filosofar, e que, assim, primeiramente é preciso se estabelecer uma longa intimidade com um problema, uma convivência com ele, uma certa fricção. Assim, se se quisesse pensar que alguém filosofou por um tratado que escrevera, vê-se que antes é preciso saber se tal pessoa coabita com a filosofia perseguida em seu tratado.

Desse modo, pensamos que, talvez, em nossas atividades de filosofia com crianças, tendo em vista a ainda imaturidade no exercício da escrita, tenhamos encontrado um modo de fazer filosofia que não esteja necessariamente vinculado

\footnotetext{
11 Não abordaremos aqui outras maneiras de escrita que Foucault assinala em outros textos como sendo importantíssimas para o exercício da Filosofia. Queremos apenas, de uma forma negativa, tirar uma certa confiabilidade extrema de certa tradição ocidental nos textos filosóficos. Para quem se interessar no assunto, ver o texto de Foucault $A$ escrita de si (2000) e A Farmácia de Platão (2005), de Jacques Derrida.
} 
ao registro escrito de pensamento. Ao contrário, o vínculo parece estar em um exercício no qual elas procurem relacionar-se com a filosofia e se tencionem, problematizando-se e problematizando o mundo que as rodeia; em uma relação lúdica com a vida que se estabelece nesse jogo de colocar problemas e procurar decifrá-los ${ }^{12}$.

A questão que nos toma nesse momento se dá em um deslocamento da questão inicial: seria, portanto, possível perceber na própria formulação de problemas o exercício do filosofar? Qual seria a característica de um problema para que ele seja filosófico? Adentremos brevemente nessa questão, pensando conjuntamente com o filósofo argentino Alejandro Cerletti (2009; 2012).

Cerletti classifica a pergunta filosófica não pelo jeito como ela é formulada ou pelo conteúdo que aborda. A pergunta ou questionamento filosófico genuíno possui uma relação intrínseca com quem a formula, porque, para que assim seja considerada, depende da intenção daquele que pergunta e quando pergunta. Assumindo-se isso, considera-se que um mesmo questionamento pode ser ou não filosófico, dependendo daquilo que se espera como resposta. Assim, não há uma natureza filosófica dos problemas filosóficos. É possível, então, perguntar "o que é a vida?" em uma perspectiva biológica ou filosófica; enquanto na primeira a abordagem é mais técnica, a intencionalidade da segunda se funda na aspiração de um saber sem supostos. Para Cerletti, a justificativa é a de que:

[...] o perguntar filosófico não se conforma com as primeiras respostas que costumeiramente são oferecidas, que, em geral, interrompem o perguntar pelo aparecimento dos primeiros supostos. Mas, como um saber sem supostos é impossível, o questionar do filósofo é permanente. (CERLETTI, 2009, p. 24).

O perguntar filosófico é, assim, um movimento motivado pelo amor ao conhecer que nunca é alcançado, um movimento que leva a novas perguntas e, portanto, a continuar se movimentando. Para que esse movimento seja possível, é

\footnotetext{
${ }^{12}$ Pascal também parece pensar nessa maneira quando no Pensamento 331 afirma: "Em geral, só imaginamos Platão e Aristóteles com grandes túnicas de pedantes. Eram pessoas honestas e, como as outras, rindo com o seus amigos; e, quando se divertiram em fazer as suas Leis e a sua Política, fizeram-nas brincando. Era a parte menos filosófica e menos séria de sua vida. A mais filosófica consistia em viver simples e tranquilamente" (PASCAL, 1979, p.119).
} 
necessário que haja uma relação de anseio pelo saber. Encarado da maneira com a qual o apresentamos, dificilmente o filosofar poderá ser demarcado. Aparentemente, parece que nos deparamos com outro limite do ensino da Filosofia: não se sabe seguramente que o outro aprendeu filosofia.

Nesse sentido, afirma Cerletti: "[...] num sentido estrito, só quem "aprende" filosofia poderia dizer "aprendi". Só ele poderia ser a medida real de sua aprendizagem filosófica, já que qualquer mudança real supõe uma transformação subjetiva." (CERLETTI, 2009, p. 86). Desse modo, a filosofia não pode ser em nenhuma medida ensinada através de uma fórmula didática. A aposta de Cerletti é a de que ela, a filosofia, talvez possa ser transmitida pelo entusiasmo de quem a tem, ou que, por esse mesmo ato enérgico, se possa contagiar os demais. Nessa proposição, vemos ressoar o pensamento do filósofo francês que foi responsável pela criação do Curso de Filosofia na USP, Jean Maugüé. Para ele, o ensino da filosofia vale o que vale o seu professor:

Muito longe está a filosofia de ser uma "matéria" que se ensine. O filósofo é um espírito que trabalha diante de outros espíritos, sendo que, dêste modo, tudo depende do filósofo. Assim como a fôrça de uma paixão está tôda no poder daquele que a sente, no seu coração e na sua inteligência, assim o ensino da filosofia, isto é, a paixão da filosofia vai tão longe quanto a reflexão daquele que a professa (MAUGÜÉ, 1955, p.644).

Porém, parece-nos que isso não basta para que o filosofar se produza. Muitas vezes em nossas atividades sentíamos que lançávamos problemas que para nós eram filosóficos, mas que não afetavam as crianças. Pensávamos em problemas que seriam importantes que elas pensassem para que suas condições sociais e críticas fossem transformadas, mas que possivelmente elas não formulariam por si próprias. O que notamos foi que nosso fazer filosófico não era suficiente para que o fazer filosófico nelas fosse produzido. Elas percebiam, destarte, que o que fazíamos não era presente em suas vidas, e, assim, pouco se atentavam. Segue-se daí que, se se quer ensinar filosofia, é preciso preparar um ambiente no qual se criem condições para a formulação de perguntas filosóficas, $e$ 
onde se possa também começar a perseguição de encontrar respostas (CERLETTI, 2009, p. 20-21).

Fez-se necessário, dessa maneira, questionarmo-nos: de que modo poderse-ia criar um ambiente no e pelo qual a filosofia ganhe mais possibilidade de ser exercida? Entendemos que para que isso ocorra, é preciso fazer com que problemas filosóficos sejam enunciados e a procura por respostas, iniciada.

\section{Experiência de choque e uma certa comunidade de investigação no âmbito do Ensino da Filosofia com crianças}

O primeiro indicativo de resposta que emerge das atividades que realizamos é a hipótese de que, caso se consiga estabelecer um ambiente no qual a filosofia ganhe mais possibilidade de ser exercida, esse ambiente tem de permitir um certo estranhamento do sujeito face ao mundo e ter a si mesmo problematizado de uma maneira que anseie pelo saber, embora talvez nunca o atinja. É preciso que se experiencie uma sensação de incerteza, de dúvida e também de insatisfação face ao mundo. Mas dois problemas se fazem presentes: 1) o que é essa experiência? e 2) como ela seria possível?

Costuma-se pensar que experiência é algo que se possui, algo que se acumula com o passar da vida. Em vista disso, uma criança não poderia filosofar, pois ela ainda não conhece as coisas da vida, ela não tem a experiência acumulada (Bildung) que daria condições para que pudesse realizar tal feito. Assim, poderíamos dizer com Walter Benjamin em um texto de 1913 que:

[...] cada vez mais, somos tomados pelo sentimento de que a nossa juventude não passa de uma curta noite (vive-a plenamente, com êxtase); depois vem a grande "experiência", anos de compromisso, pobreza de ideias, lassidão. Assim é a vida, dizem os adultos, eles já experimentaram isso. (BENJAMIN, 2002, p. 22)

No entanto, sugere Benjamin (BENJAMIN, 2002, p. 24) que somos capazes de uma outra experiência. Uma outra experiência de vivência do espírito ${ }^{13}$, o que

${ }^{13}$ Uma nota negativa: o termo espírito, na língua portuguesa, é mais associado a conotações religiosas e a figuras transcendentes. Entretanto, em alemão, espírito - Geist - denota mais algo relacionado ao homem do que os sentidos acima 
talvez seja hostil a ele e capaz de destruir sonhos, embora seja ela o que existe de mais belo em nossa vida. Em contrapartida, há a experiência do filisteu que vive sem o espírito ocupando, assim, uma posição confortável frente a vida, todavia funesta.

Procurando, então, mais indícios do que seja tal experiência, encontramos alguns elementos em outro texto do filósofo alemão, esse um pouco mais tardio, de 1933, intitulado Experiência e Pobreza (1986).

Benjamin começa-o com uma fábula bastante conhecida de um velho que, prestes a morrer, divulga a seus filhos a existência de um tesouro escondido em sua vinha. Para encontrá-lo, seus filhos deveriam somente cavar. Então cavaram incessantemente, mas não encontraram o tesouro. Não obstante, com a chegada do outono a vinha produziu imensamente. Assim, os filhos perceberam que o pai lhes legara uma experiência sobre a importância do trabalho.

A partir dessa fábula Benjamin constata o quão pobre eram os homens de seu tempo em experiências ${ }^{14}$. Diz ele: "Sim, admitamos: essa pobreza de experiências não é uma pobreza particular, mas uma pobreza de toda a humanidade. Trata-se de uma espécie de nova barbárie" (BENJAMIN, 1986, p. 196). Desse modo, pode-se concluir que o vinhateiro possibilitou que seus filhos tivessem uma experiência por si sós. Ele não informou algo pré-determinado a ser feito, apenas forneceu indícios, pistas, pegadas para que eles pudessem fazer a experiência.

Amparados nessas considerações de Benjamin, pudemos concluir que é de grande importância no ensino da Filosofia indicar - endéixis, como Foucault já havia nos soprado aos ouvidos - e sugerir outras experiências para as crianças através de problemas e situações que as façam ter uma experiência de choque (Erlebnis), conforme a interpretação que Morey (2007) faz de Benjamin.

referidos. Sinal disso é que ciências humanas, ou humanidades, na Alemanha chamam-se Geisteswissenschaften.

14 Há duas palavras em alemão que geralmente são traduzidas para o português como experiência: Erlebnis e Erfahrung. Segundo Morey (2007), pode-se entender Erfahrung como uma experiência durável, e Erlebnis como uma experiência vivida intensamente e de choque. Essa última é relacionada ao método do passeante de Benjamin, o qual procura acontecer escapando de qualquer vontade de reconhecimento, e abrindo-se para a possibilidade de um encontro. 
Considerada do modo como a tratamos, tal experiência, quando exercida pelas crianças, será autêntica e possibilitante de diversos sentidos, quiçá, uma experiência de pensamento sem supostos, uma experiência do filosofar. Em suma, é preciso que se crie um ambiente no qual outras experiências sejam possíveis e possibilitantes de outras matérias para o filosofar.

Ainda na tentativa de criar um ambiente propício à experiência filosófica, assumimos alguns posicionamentos expostos por Matthew Lipman (2001), quando descreve a transformação da sala de aula em uma comunidade de investigação. $\mathrm{O}$ autor acredita que, quando as crianças são incentivadas a pensar filosoficamente, essa comunidade é formada no intuito de se pensar em conjunto na procura de perguntas e respostas que sejam pertinentes e razoáveis ${ }^{15}$. Deve-se, portanto, manter o tensionamento no problema e na formulação de respostas a ele a fim de criar condições para que as crianças possam se expressar da melhor forma possível seus pontos de vistas e deixem claros seus argumentos. Assim, as crianças podem se conduzir, e não mais serem conduzidas, para onde suas próprias ideias as levem, sem um direcionamento ou manipulação vinda de nós.

Nossa intenção principal é a de fazer com que as crianças possam pensar por si mesmas, e para isso:

(...) pressupõe-se que as crianças aprendem ao estarem envolvidas ativamente em uma exploração, bem como que o conhecimento não é algo que simplesmente se aprende automaticamente, mas sim algo que se domina através da interação com o ambiente e solucionando problemas que são importantes para as crianças (LIPMAN, 2001, p. 119).

15 A crítica de Renê Silveira (2001) a razoabilidade de Lipman aparece-nos um pouco reducionista, pois tal conceito do estadunidense é amparado no conceito de razoável de Charlles Sander Peirce, fazendo com que este atinja um sentido cosmológico que a primeira vista Silveira não percebe, e tampouco cita o pragmaticista em sua tese de doutorado. Para leitores interessados na relação pouco estudada entre Lipman e Peirce, também sublinhamos o fato de que a autocorreção da comunidade de investigação proposta por Lipman foi igualmente extraída de Peirce: "A noção de que os membros de uma comunidade que exercitam a crítica serão capazes de internalizar esta prática como autocrítica, passando, deste modo, da posição de autocrítica para a de autocorreção, é derivada de "Ideals of Conduct", em Charles Hartshorne e Paul Wiess (eds.), Collected Papers of Charles Sanders Peirce, 8. vols. (Cambridge, Massachusetts: Harvad University Press, 1965-6), vol. 1, p.591-615. O movimento estratégico aqui é da falibilidade epistemológica à falibilidade ética. É o texto comum da comunidade de investigação que torna possível a passagem da investigação epistemológica para a investigação ética " (LIPMAN, 1995, p.111). 
Para que a aprendizagem do pensamento filosófico seja efetivada, são necessárias quatro condições segundo Lipman: (i) comprometer-se com a investigação filosófica; (ii) evitar a doutrinação; (iii) respeitar as opiniões das crianças; e (iv) despertar a confiança delas.

Analisando essas condições no projeto que realizamos, a confiança é despertada pelo incentivo para que elas falem o que pensam, que pensem sobre o que é discutido e pela afirmação de que, qualquer que seja sua opinião, ela é importante e relevante. Em relação ao respeito, ele deve existir entre nós e as crianças e entre elas. Esse segundo modo é o mais difícil de obter, haja vista as condições em que convivem. Entretanto, é algo sempre que deve ser sempre intensificado, para que, talvez, em algum momento possam assumir essa atitude de respeito por elas mesmas.

Dado que as crianças participantes do projeto e nós vivemos em contextos diferentes, apesar de partilharmos o mesmo ambiente no desenvolvimento das atividades, surge a dificuldade de saber o que é relevante para elas. Esse problema é conduzido por constantes tentativas e erros na procura de uma possível solução. Juntamente a isso, também é necessário sensibilidade em ouvir e perceber as respostas delas àquilo que conseguíamos construir conjuntamente. Daí, conclui-se com o autor que: "O que se pode fazer é criar um ambiente favorável para o bem pensar, e reconhecer que as crianças têm diferentes estilos de comportamento mental, cada um dos quais necessita ser alimentado de forma mais ou menos diferente" (LIPMAN, 2001, p. 127). Contudo, a implantação desse ambiente levou tempo porque, mais uma vez, nosso objetivo era fazer algo com e não para as crianças.

\section{Considerações finais}

Em nosso Epílogo há uma fala de Sócrates n' O Banquete. Como seria bom, afirma ele, se a sabedoria fosse de natureza tal que escorresse de alguém mais cheio a alguém mais vazio. Com efeito, o trabalho do educador seria muito menor e certamente mais fácil. 
No entanto, frente a tudo que vivenciamos com as crianças do "Projeto (nome do projeto)" ao longo do presente ano, e com os autores que nos moveram em diferentes perspectivas sugerindo-nos criativas maneiras de pensar o ensino da Filosofia, concluímos que o trabalho do professor não é levar algo a alguém, especialmente quando o assunto é a filosofia.

Não. Não levamos a filosofia às crianças, mas procuramos criar com elas uma filosofia que, de certo modo, foi sendo pensada no desenvolvimento dos problemas e de suas soluções. Criamos experiências que, quando de fato acontecem, podem ou não tornarem-se duráveis. Entretanto, criamos experiências que vão além de "encher ou esvaziar" uma pessoa, criamos experiências insistentes.

A insistência é caracterizante de um movimento problematizador que surgia em algumas crianças conforme eram afetadas por algo que lhes forçava pensar. Nesse sentido, uma vez que criavam um problema, elas se enchiam de uma agitação caracterizada pela busca de novas soluções que, por sua vez, continuam suportando o problema e, por sua força, reformulando-se.

Com isso, tentamos libertar-nos de uma imagem dogmática do pensamento $^{16}$ chamada a modalidade das soluçôes levantada por Gilles Deleuze (1988). Segundo ela, os problemas já estão dados e desaparecem em sua solução; por conseguinte, fazer filosofia seria mais buscar soluções do que criar problemas $e$ tentar solucioná-los indefinitivamente.

Em todo caso, sabemos que somente elas, as crianças, podem nos assegurar dizendo para si que realmente aprenderam a filosofia e seu exercício. Entretanto, também sabemos que foram esses limites que nos permitiram pensar outras veredas para realizar a Filosofia, veredas que vimos surgirem motivando filosoficamente as próprias atividades...

Assim, só nos resta um sentimento grande de gratidão para com as crianças com as quais trabalhamos, e especialmente a uma de 9 anos que afirmou em um

16 Em linhas gerais, por imagem dogmática de pensamento pode-se entender os pressupostos tanto objetivos quanto subjetivos que regulam uma maneira de pensamento filosófico. Para escapar a elas, é necessário criar um modo menor de fazer filosofia, caso entenda-se por menor não uma inferioridade ligada a algo ou um número pequeno de pessoas, mas algo que fuja de uma maneira que se impõe frequentemente, uma maneira maior. 
dia sem tempo: "Morte não é só morrer, morte é você esquecer de si mesmo, né. É você nem ligar para o que está acontecendo, para onde você está..."

\section{Referências}

AGAMBEN, Giorgio. O que é o contemporâneo? E outros ensaios. Tradução de Vinícius Nicastro Honesko. Chapecó, SC: Argos, 2009.

ANDRADE, Carlos Drummond de. A rosa do povo. São Paulo: Companhia das Letras, 2009.

ARISTÓTELES. Metafísica vols. II, III, $2^{a}$ edição. Tradução do texto grego, sumário e comentários de Giovanni REALE. Tradução portuguesa, Marcelo Perine. São Paulo, Edições Loyola: 2002.

BÁRCENA, F. Pedagogía de La Presencia. Voces para uma educacíon en la filiación del tiempo, Universidad Complutense de Madrid, p. 1-19, 2010.

BENJAMIN, Walter. Experiência e pobreza. In:

Documentos de cultura, documentos de barbárie: escritos escolhidos. São Paulo: Cultrix, 1986. p.195-8.

. Walter. Reflexões sobre a criança, o brinquedo $e$ a educação. Tradução de Marcus Vinícius Mazzari. São Paulo: Duas Cidades; Ed. 34, 2002.

CERLETTI, Alejandro. O ensino de filosofia como problema filosófico. Tradução de Ingrid Müller Xavier. Belo Horizonte: Autêntica Editora, 2009.

. El curso filosófico: supuestos y posibilidades. Florianópolis, Revista Linhas, v. 13, n. 01, p. 123 - 131, jan. / jun. 2012.

DELEUZE, Gilles. Diferença e repetição. Tradução: Luiz Orlandi, Roberto Machado. Rio de Janeiro: Graal, 1988.

DERRIDA, Jacques. A Farmácia de Platão. Tradução de Rogério da Costa. São Paulo: Illuminuras, 2005.

FOUCAULT, Michel. A escrita de si. In: . O que é um autor? 4. ed. São Paulo: Vega, 2000. p. 129-160.

O governo de si e dos outros: curso no Collège de France. Tradução de Eduardo Brandão. São Paulo: Editora WMF Martins Fontes, 2010.

Paulo: Martins Fontes, 2011;

A Hermenêutica do Sujeito. Salma Tannus Muchail, $3^{\mathrm{a}}$ ed, São

FREIRE, Paulo. Pedagogia do oprimido. 50 ed. Rio de Janeiro: Paz e Terra, 2011.

GELAMO, R. P. O ensino da filosofia no limiar da contemporaneidade: o que faz o filósofo quando seu ofício é ser professor de filosofia? São Paulo: Cultura Acadêmica, 2009.

KOHAN, Walter Omar; OLARIETA, Beatriz Fabiana (Org.). A escola pública aposta no pensamento. Belo Horizonte: Autêntica Editora, 2012. 
LIPMAN, Matthew. A filosofia vai à escola. Tradução de Maria Elice de Brzezinski Prestes e Lucia Maria Silva Kremer. São Paulo: Summus, 1990.

Perpétuo. Petrópolis, RJ: Vozes, 1995.

O pensar na educação. Tradução de Ann Mary Figghiera

A filosofia na sala de aula. Matthew Lipman, Ann Margaret Sharp, Frederick S. Oscanyan; tradução de Ana Luiza Fernandes Marcondes. - São Paulo: Nova Alexandria, 2001.

MAUGÜÉ, Jean. O ensino da filosofia: suas diretrizes. Revista Brasileira de Filosofia, São Paulo. v.5, fasc.4, n.20, p.642-9, 1955.

MOREY, M. Pequeñas doctrinas de la soledad. Madrid: Sexto Piso, 2007.

PASCAL, Blaise. Pensamentos. Tradução de Sérgio Milliet. $2^{\mathrm{a}}$ ed. São Paulo: Abril Cultural (Os Pensadores), 1979.

PLATON. Cartas. Edición bilingüe y prólogo por Margarita Toranzo. Madrid: Instituto de Estudios Políticos, 1954.

RANCIÈRE, J. Uma Aventura Intelectual, IN: O mestre ignorante: cinco lições sobre emancipação intelectual. Belo Horizonte: Autentica, 2002.

SILVEIRA, Renê J. T. A filosofia vai à escola?: contribuição para a crítica do Programa de Filosofia para Crianças de Matthew Lipman. Campinas: Autores Associados, 2001. 